\title{
Elucidation of Sorption Mechanism of R. arrhizus for Reactive Blue 222 using Equilibrium and Kinetic Studies
}

\author{
Sukhada Saraf* and Varsha K Vaidya \\ The Institute of Science, Madam Cama Road, Mumbai, Maharashtra, India
}

\begin{abstract}
The equilibrium and kinetics of the biosorption of Reactive Blue 222 from aqueous solution were investigated using dead biomass of Rhizopus arrhizus in a batch system. Biosorption equilibrium was established in about 180 min. The sorption data obtained at $\mathrm{pH} 1.5$ conformed well to the Langmuir isotherm model. The Reactive Blue 222 biosorption data were analyzed using the pseudo-first, the pseudo-second order, Elovich kinetics models as well as intra-particular rate diffusion and liquid film diffusion. The second-order equation was the most appropriate equation to predict the biosorption capacities of the biosorbent. The reusability of the biosorbent was tested in five consecutive adsorption-desorption cycles and the regeneration efficiency was above $97 \%$. The XRD, SEM, FITR analyses helped to elucidate the mechanism of biosorption. From the practical viewpoint, the abundant and inexpensive dead fungal biomass could be used as an effective, low cost and environmentally friendly biosorbent for the removal of Reactive Blue 222 from the aqueous solution.
\end{abstract}

Keywords: Biosorption; Isotherms; Kinetics; Reactive Blue 222; Rhizopus arrhizus

\section{Introduction}

India's dye industry produces all types of dyes such as disperse, reactive and direct dyes, which are used extensively in textile, paper, printing industries and dye houses. Textile industry is one of the most water- and chemical-intensive industries worldwide and leaves one of the largest water footprints on the planet $[1,2]$. Of all the dyed textile fibers, cotton occupies the number-one position and more than $50 \%$ of its production is dyed with reactive azo dyes, owing to their technical characteristics such as bright and water-fast colors, simple application techniques with low energy consumption. Unfortunately, this class of dyes is also the most unfavorable one from the ecological point of view, as the effluents produced are relatively heavily colored, contain high concentrations of salt and exhibit high BOD/COD values [3]. The release of colored wastewater in the ecosystem is a prominent source of aesthetic pollution, eutrophication and perturbations in natural equilibrium of the aquatic environment [4]. Dyes, even at very low concentrations are often toxic, carcinogenic or mutagenic for various organisms [5].

Textile dyes are designed to resist fading upon exposure to sweat, light, water, oxidizing agents, which limits the application of various physico-chemical treatment methods like chemical precipitation, reverse osmosis, ozonation, membrane filtration, photo-degradation, etc. [6,7]. Unfavourable conditions found in the textile dyeing effluents are known to inhibit the conventional biological treatment processes. Moreover, various azo dyes have been shown to be anaerobically decolorized by the cleavage of azo bond, resulting in the formation of potentially carcinogenic aromatic amines [7].

Thus, the treatment of textile effluents is under the strong radar of the environmental agencies making it imperative to take new initiatives for environmental restoration and provide inexpensive and reliable method for the removal of dyes. Among all the wastewater treatments, the adsorption process has been recognized to be an effective and economical procedure for the elimination of dyes from the industrial effluents. Adsorption can handle large flow rates, producing a high-quality effluent that does not result in the formation of harmful substances. Activated carbon is one of the most widely used adsorbents because of its excellent adsorption capacity for organic pollutants. However, high costs, difficulty in regeneration, problems with regard to final disposal, inefficient adsorption of cationic dyes limit its commercial application [8-10]. Hence, low-cost biosorbents such as waste materials from industry and agriculture, as well as biosorbents derived from microbial biomass (yeasts, fungi, algae, etc.) with high adsorption capacities have gained increasing attention in reducing the adsorbent dose and minimizing the disposal problem [11,12].

Application of fungal biomass to remove textile dyes from the effluent is attractive for industry as it may decrease the overall effluent treatment costs. Industrial fermentation processes can provide a cheap and constant supply of fungal biomass or the biomass can be cultured using inexpensive growth media and unsophisticated fermentation techniques. Traditionally, the fungal biomass by-product is incinerated for disposal or used as a fertilizer for agricultural use. Due to its poorly biodegradable biopolymers (cellulose, chitin, glucans, etc.) fungal biomass used as a fertilizer has a low economic value. However, it is possible to consider the potential economical reuse of the biomass in the biosorption of dyes [13]. There are many advantages of using inactivated mycelium for biosorption such as easy storage, selectivity, high removal rates, low costs and regenerative potential. The efficiency of the biosorption of reactive azo dyes by some fungi under equilibrium conditions has been shown to be more than that of activated carbon [14].

The efficiency of the sorption process is governed by the cost and performance of a sorbent as well as the mode of application. Hence, an attempt was made to evaluate two vital elements of the adsorption process viz. equilibrium of the sorption and the sorption kinetics

*Corresponding author: Sukhada Saraf, The Institute of Science, Madam Cama Road, Mumbai, Maharashtra, India, Tel: +919969574411; E-mail: saraf_sukhada@yahoo.co.in

Received May 25, 2016; Accepted June 07, 2016; Published June 14, 2016

Citation: Saraf S, Vaidya VK (2016) Elucidation of Sorption Mechanism of $R$. arrhizus for Reactive Blue 222 using Equilibrium and Kinetic Studies. J Microb Biochem Technol 8: 236-246. doi: 10.4172/1948-5948.1000292

Copyright: () 2016 Saraf S, et al. This is an open-access article distributed under the terms of the Creative Commons Attribution License, which permits unrestricted use, distribution, and reproduction in any medium, provided the original author and source are credited. 
$[15,16]$. Adsorption isotherms are critical for predictive modelling and comparing the adsorption performance, besides providing a view on the degree of affinity of the adsorbents, adsorption mechanism and course taken by the system under study in a concise form. In this research, four isotherm models viz. Langmuir, Freundlich, Temkin and Dubinin-Radushkevich (D-R) models were used to verify the affinity between Rhizopus arrihizus biosorbent and Reactive Blue 222 (RB 222) dye, a commonly used dye in the Indian textile industry. The kinetics data were used to identify the adsorption mechanism and the rate limiting step. Surface characterization of the biosorbent was done using XRD, SEM, FTIR analyses, modification of functional groups on the biosorbent and determination of $\mathrm{pH}_{\mathrm{zpc}}$.

\section{Materials and Methods}

\section{Preparation of adsorbate}

Reactive Navy Blue BF (C.I. Reactive Blue 222, CAS 93051-446, chemical formula: $\mathrm{C}_{37} \mathrm{H}_{23} \mathrm{ClN}_{10} \mathrm{Na}_{6} \mathrm{O}_{22} \mathrm{~S}_{7}, \mathrm{MW}: 1357.49 \mathrm{gmol}^{-1}$ ) a bifunctional diazo reactive dye (Figure 1 ) was obtained as a solid powder from DyStar, India and used without further purification. Stock solution of the dye $\left(1 \mathrm{gL}^{-1}\right.$ at $\left.\mathrm{pH} 1.5\right)$ prepared in double distilled water was diluted to obtain solution of desired concentration $\left(88 \mathrm{mgL}^{-1}\right)$ for experimental purpose. The $\mathrm{pH}$ of the solution was measured using a $\mathrm{pH}$ meter (Control Dynamics, India). All the chemicals and reagents used for experiments were of analytical grade and supplied by HiMedia, Mumbai, India [17].

\section{Preparation of the biosorbent}

Fungal biomass was acquired by aseptically transferring mycelia from the potato dextrose agar (PDA) spread-plate cultures to 100 $\mathrm{mL}$ of potato dextrose broth $(\mathrm{PDB})\left(\mathrm{gL}^{-1}\right.$ : potato infusion from 200 g potatoes, dextrose 20 , yeast extract $0.1, \mathrm{pH} 5.0$ ) containing $0.25 \%$ Tween 80 (to prevent sporulation) in $250 \mathrm{~mL}$ Erlenmeyer flasks. The biomass was harvested after seven days of incubation at $30 \pm 1^{\circ} \mathrm{C}$ under static conditions with sporadic shaking. The biomass was then washed thoroughly with double distilled water and dried at $80^{\circ} \mathrm{C}$ for $24 \mathrm{~h}$. The size of the biomass particles was kept uniform by grinding into a fine powder and sieving through a 150 -mesh sieve. Dried biomass was preserved in a desiccator till further use [17].

Characterization of the surface chemistry of the biosorbent: Surface characterization of the dead biomass of $R$. arrhizus was carried out before and after biosorption with RB 222. X-Ray Diffraction (XRD) analysis, a very powerful tool to study the nature of the biosorbent, was used to assess the presence of crystalline phases present in the biosorbent. X-ray diffraction patterns were recorded in a scanning mode using Rigaku Miniflex X-ray diffractometer equipped with a $\mathrm{Cu}$ target having wavelength of $1.54 \mathrm{~A}^{\circ}$ with $2 \theta$ angle varying between $5^{\circ}$ and $80^{\circ}$. Scanning Electron Microscope (SEM) (Philips XL 30 SEM) was employed to study the surface morphology and fundamental physical properties of the biosorbent surface at $10 \mathrm{KV}$ with tilt angle of $45^{\circ}$. Fourier Transform Infrared Spectroscopy(FTIR) (Shimadzu 8400S) analysis of the biosorbent was carried out over a spectral range varying from $4,000 \mathrm{~cm}^{-1}$ to $400 \mathrm{~cm}^{-1}$ to identify the characteristic functional groups responsible for biosorption. The infrared spectra were obtained and averaged over 32 scans in the transmission mode (Figures 1-4).

Modification of functional groups on the biosorbent: The chemical modification of amino $\left(-\mathrm{NH}_{2}\right)$ and carboxylic groups ($\mathrm{COOH})$ as well as the extraction of lipids was carried to study the extent of their involvement in biosorption. Methylation of amines was carried out by treating $1 \mathrm{~g}$ of biosorbent with $20 \mathrm{~mL}$ of formaldehyde and $40 \mathrm{~mL}$ of formic acid. Esterification of carboxylic acids was carried out by suspending $1 \mathrm{~g}$ of biosorbent in $65 \mathrm{~mL}$ of ethanol and $0.6 \mathrm{~mL}$ of concentrated hydrochloric acid. Both the mixtures were shaken separately for $5 \mathrm{~h}$ at $150 \mathrm{rpm}$. Extraction of lipids was carried out by heating $1 \mathrm{~g}$ of biosorbent in $75 \mathrm{~mL}$ of benzene under reflux conditions for $6 \mathrm{~h}$. After all the treatments, the solutions were filtered using Whatman No. 42 filter paper and the biosorbent was washed with distilled water to remove all the traces of the chemicals and dried at $80^{\circ} \mathrm{C}$ for $8 \mathrm{~h}$. The effect of each functional group modification was studied by measuring the change in biosorption capacity of the biosorbent $[18,19]$.

Determination of zero point of charge $\left(\mathrm{pH}_{\mathrm{zpc}}\right)$ : The zero point of charge $\left(\mathrm{pH}_{z \mathrm{pc}}\right)$ is a point at which the charge of the solid surface is zero and the surface acidic (or basic) functional groups no longer contribute to the $\mathrm{pH}$ value of the solution. The determination of $\mathrm{pH}_{\mathrm{zpc}}$ of the chosen biosorbent was done by introducing $0.1 \mathrm{~g}$ biomass each into nine $100 \mathrm{~mL}$ Erlenmeyer flasks containing $50 \mathrm{~mL}$ of $0.1 \mathrm{M}$ potassium nitrate solution. Initial $\mathrm{pH}$ values of the nine solutions were adjusted between $2-10$ by adding either $0.1 \mathrm{M} \mathrm{HNO}_{3}$ or $\mathrm{NaOH}$. The solutions were then allowed to equilibrate on an orbital shaker (Labtop Quality Lab Equipment, India) $\left(30 \pm 1^{\circ} \mathrm{C}\right)$ for $48 \mathrm{~h}$ at $150 \mathrm{rpm}$. The suspension in each sample was then filtered and the final $\mathrm{pH}$ was measured again. The $\mathrm{pH}_{\mathrm{zpc}}$ is the point where the curve of $\mathrm{pH}$ final $\left(\mathrm{pH}_{\text {final }}\right)$ versus $\mathrm{pH}$ initial $\left(\mathrm{pH}_{\text {initial }}\right)$ crosses the line [20].

\section{Equilibrium studies}

Batch biosorption experiments were performed in $250 \mathrm{~mL}$ Erlenmeyer flasks containing $50 \mathrm{~mL}$ of reaction mixture by using conditions optimized earlier (results not shown) under following conditions: $\mathrm{pH}$ 1.5,RB 222 dye concentration $88 \mathrm{mg} \mathrm{L}^{-1}$, biosorbent concentration $1.2 \mathrm{~g} \mathrm{~L}^{-1}$, temperature $35^{\circ} \mathrm{C}$, speed of agitation $80 \mathrm{rm}^{-1}$. Samples were withdrawn at definite intervals of $20 \mathrm{~min}$ over a period of $240 \mathrm{~min}$ for determination of the residual colour in the solution after centrifuging at $4000 \mathrm{rm}^{-1}$ for $10 \mathrm{~min}$. The concentration of the dye in the solution was determined from the calibration curve prepared by measuring the absorbance of known concentrations of RB 222 at $609 \mathrm{~nm}$ using UV-Vis Spectrophotometer (Shimadzu, Japan UV1800 UV/VIS) reporting each data point as an average value of the triplicates recorded. Simultaneously a blank without biosorbent was run as a control. The concentration of the dye on the fungal biomass at the corresponding equilibrium conditions was determined using a mass balance equation expressed as specific uptake capacity (SUC) [21].

$$
Q_{e}=\frac{\left(C_{0}-C_{t}\right) * V}{M}
$$

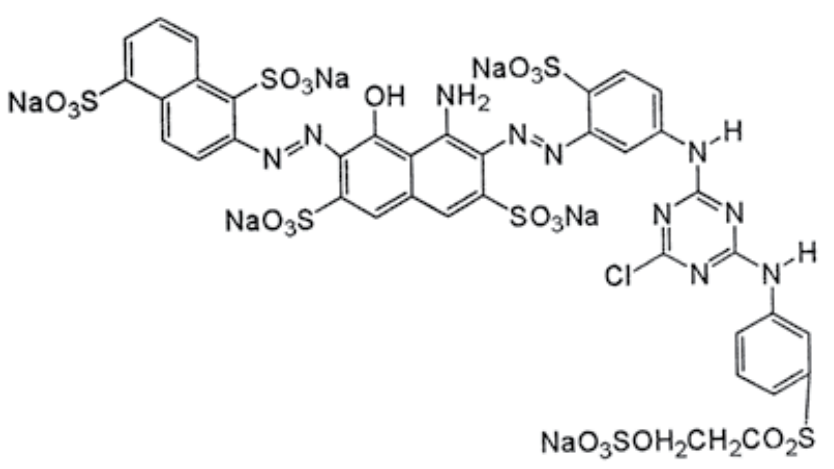

Figure 1: Structure of RB 222 
Citation: Saraf S, Vaidya VK (2016) Elucidation of Sorption Mechanism of $R$. arrhizus for Reactive Blue 222 using Equilibrium and Kinetic Studies. J Microb Biochem Technol 8: 236-246. doi: 10.4172/1948-5948.1000292

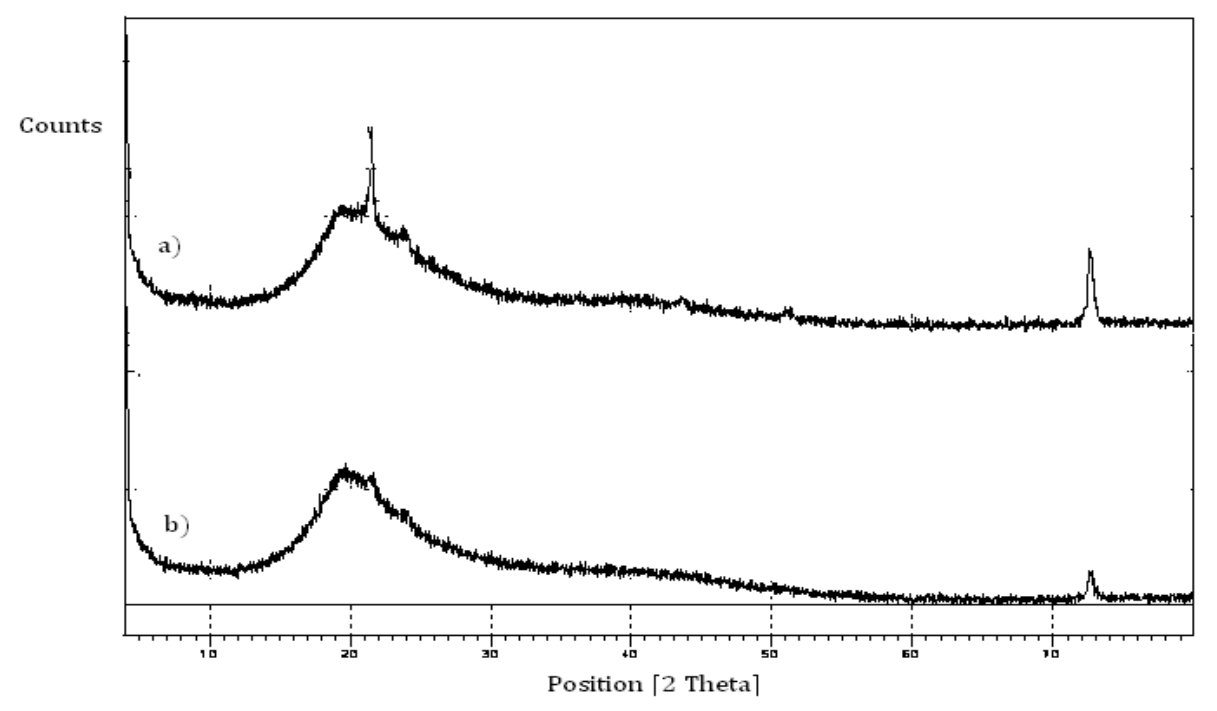

Figure 2: XRD spectra of a) Biosorbent after adsorption with RB 222and b) Biosorbent before adsorption with RB 222.

a)

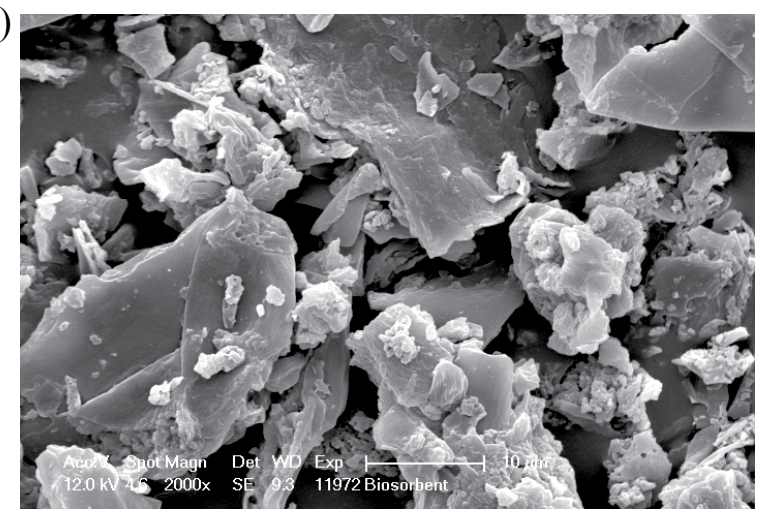

b)

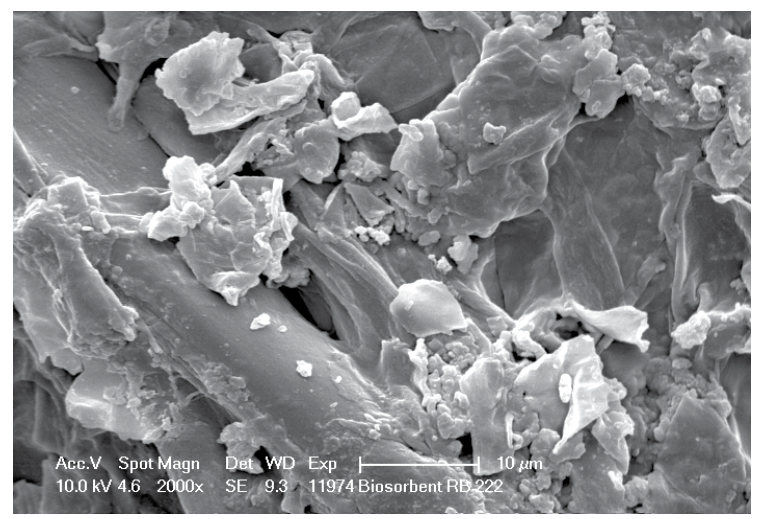

Figure 3 a) Biosorbent before adsorption with RB 222 and b) Biosorbent after adsorption with RB 222.

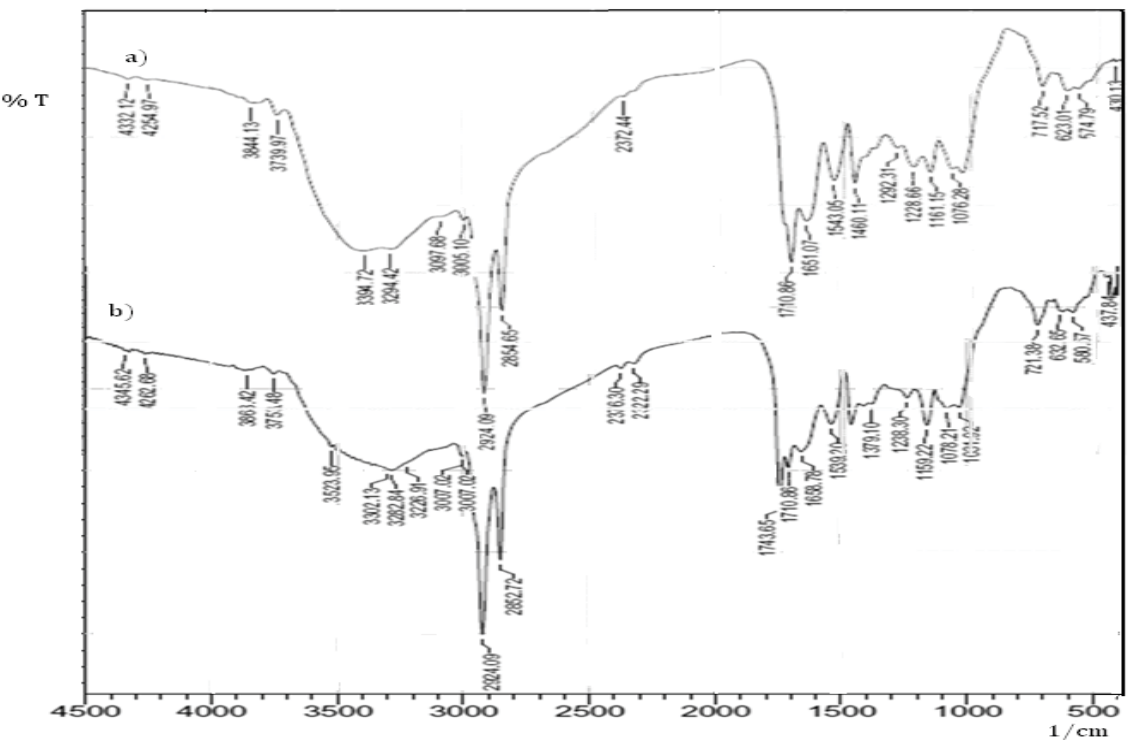

Figure 4: FTIR spectra of a) Biosorbent after adsorption with RB 222 and b) Biosorbent before adsorption with RB 222. 
Where, $C_{0}$ and $C_{t}$ are the initial and final concentrations $\left(\mathrm{mgL}^{-1}\right)$ respectively, $M$ is the biosorbent dosage ( $\mathrm{g}$ ) and $V$ the volume of the solution (L) [17].

Isotherm models: In an endeavour to effectively design, develop and optimize an ideal adsorption system and to study the performance of an adsorbent it is essential to establish the most fitting adsorption equilibrium correlation for reliable prediction of the adsorption parameters. In this regard, equilibrium relationships, known as adsorption isotherms, describe how pollutants interact with the adsorbents [22,23]. In addition, the quality of the fit of the experimental results indicates whether adsorption is monolayer or multilayer, on a homogeneous or a heterogeneous surface [24]. below:

The linearized form of Langmuir adsorption isotherm is given

$$
\frac{C_{e}}{q_{e}}=\frac{1}{K_{L} q_{m}}+\frac{C_{e}}{q_{m}}
$$

Where, $q_{m}$ is the maximum monolayer adsorption capacity ( $\mathrm{mg} / \mathrm{g}$ ), $K_{L}$ is the Langmuir constant $(\mathrm{Lm} / \mathrm{g})$, and $q_{e}$ and $C_{e}$ are the adsorption capacity $(\mathrm{mg} / \mathrm{g})$ and equilibrium concentration $(\mathrm{mg} / \mathrm{L})$, respectively. A straight line of slope $1 / q_{m}$ and intercept $1 / K_{L} q_{m}$ is obtained by plotting $C_{e} / q_{e}$ versus $C_{e}[25]$.The dimensionless biosorption intensity $\left(R_{L}\right)$ is calculated using the following equation:

$$
R_{L}=\frac{1}{1+\left(1+K_{L} C_{0}\right)}
$$

Where, $C_{o}$ is the initial concentration in the solution $(\mathrm{mg} / \mathrm{L})$.

Freundlich isotherm is the earliest known relationship describing the non-ideal, reversible and heterogeneous adsorption due to the diversity of adsorption sites [26] and its linear expression is given as:

$$
\ln q_{e}=\ln \left(K_{F}\right)+\frac{1}{n} \ln \left(C_{e}\right)
$$

Where, $K_{F}$, an empirical constant, is defined as a sorption coefficient representing the amount of dye molecules for a unit equilibrium concentration and is related to the sorption capacity of the sorbent. Slope, $1 / n$ is an empirical constant related to the intensity of sorption and varies with surface heterogeneity and affinity.

Temkin isotherm contains a factor that explicitly takes into account adsorbent-adsorbate interactions. By ignoring the extremely low and high values of concentrations, the model assumes that the adsorption is characterized by a homogenous distribution of binding energies, up to a maximum binding energy [27]. The linearized form of Temkin isotherm is given as:

$$
q_{e}=B \ln A_{T}+B \ln C_{e}
$$

Where, $B(=R T / b)$ in $(\mathrm{J} / \mathrm{mol})$ is related to the heat of adsorption, $T(\mathrm{~K})$ is the absolute temperature, $b$ is the Temkin's isotherm constant and $A_{T}(\mathrm{~L} / \mathrm{g})=\left(R T \ln A_{T}\right) / b$ is the equilibrium binding constant, corresponding to the maximum binding energy. $R$ is the universal gas constant $\left(8.314 \mathrm{Jmol}^{-1} \mathrm{~K}\right)$ [27]. A plot of $q_{e}$ versus $\ln C_{e}$ enables the determination of the isotherm constants $B$ and $A$ from the slope and intercept of the straight line plot $[25,28]$.

The D-R isotherm equation has been often used to determine the mean adsorption energy $(E)$ which may provide useful information with regard to whether or not biosorption is subject to a chemical or physical process [29]. Dubinin and Radushkevich developed the following isotherm in accounting for the effect of the porous structure of an adsorbent [30]:

$$
Q_{e}=B_{D} \exp \left(-K_{D} \varepsilon^{2}\right)
$$

Where, $B_{D}$ is the Dubinin-Radushkevich isotherm constant related to the degree of sorbate sorption by the sorbent surface representing the theoretical monolayer saturation capacity $(\mathrm{mg} / \mathrm{g}), K_{D}$ is related to the free energy of sorption per mole of the sorbate as it migrates to the surface of the biomass from infinite distance in the solution $\left(\mathrm{mol}^{2} / \mathrm{KJ}^{2}\right)$ and is related to mean adsorption energy $(E)(\mathrm{KJ} / \mathrm{mol})$ through

$$
E=\left[\frac{1}{\sqrt{2 B_{D}}}\right]
$$

The Polanyi potential $\varepsilon$ is defined by

$$
\varepsilon=R T \ln \left[1+\frac{1}{C_{e}}\right]
$$

It is apparent that the D-R isotherm equation would not be simplified to the Langmuir or Freundlich type of isotherm. Furthermore, plot of $\ln Q_{e}$ versus $\ln ^{2}\left(1+\left(1 / C_{e}\right)\right.$ should lead to a straight line, and its slope is given by

$$
\text { Slope }=-B_{D} R^{2} T^{2}
$$

Thus, the mean adsorption energy $(E)$ can be calculated as follows:

$$
E=\frac{1}{\sqrt{2 B_{D}}}=\frac{R T}{\sqrt{-2 * \text { Slope }}}
$$

Where, $B_{D}$ is denoted as the isotherm constant representing the theoretical monolayer saturation capacity $[29,30]$.

\section{Biosorption kinetics}

The kinetics represents reaction rate which determines the residence time required for completion of the sorption and elucidates reaction pathways which cannot be explained by the isotherms [31]. In the present study, five kinetics models viz. Lagergren's pseudo-first order, the pseudo-second order [32], Elovich kinetic model [33], the intraparticle diffusion model [34] and liquid film diffusion model [35] were employed, assuming that the measured concentrations are equal to cell surface concentrations. One of the most widely used equations for the sorption of the solute from a liquid solution describing the adsorption of liquid-solid systems based on solid capacity is the pseudo-first-order rate equation of Lagergren [36]. The linear form of Lagergren's pseudofirst order equation is given as:

$$
\log \left(q_{e}-q_{t}\right)=\log q_{e}-\frac{k_{1}}{2.303} t
$$

Where, $q_{e}$ and $q_{t}$ are the sorption capacity $(\mathrm{mg} / \mathrm{g})$ of the dye at equilibrium and at a time $t$, respectively, and $k_{1}$ is the rate constant for pseudo-first order sorption $(1 / \mathrm{min})$. A plot of $\log \left(q_{e}-q_{t}\right)$ against $t$ should give a straight line to confirm the applicability of the kinetic model [37].

The pseudo second-order equation, based on the sorption capacity of the solid phase, predicts the behaviour over the whole range of adsorption and is in agreement with chemisorption mechanism being the rate controlling step and the linear form pseudo-second order kinetic model is [32]:

$$
\frac{t}{q_{t}}=\frac{1}{k_{2} q_{e}^{2}}+\frac{1}{q_{e}} t
$$


Where, $q_{e}$ and $q_{t}$ are the sorption capacity $(\mathrm{mg} / \mathrm{g})$ of the dye at equilibrium and at a time $t$, respectively, and $k_{2}$ is the rate constant for pseudo-second order sorption $\left(\mathrm{gmg}^{-1} \mathrm{~min}^{-1}\right)$. In the limit $q_{t} / t=0$, the initial sorption rate, $h$, is given by $k_{2} q_{e}^{2}$. Thus, a plot of $t / q_{t}$ against $t$ of equation should give a linear relationship with a slope of $1 / q_{e}$ and an intercept of $1 / k_{2} q_{e}^{2}$, i.e., $1 / h[38]$.

Elovich equation is used successfully to describe second order kinetics assuming that the actual solid surfaces are energetically heterogeneous, but the equation does not propose any definite mechanism for adsorbate-adsorbent [33]. The linear form of the Elovich model is presented by the following equation:

$$
q_{t}=\frac{1}{\beta} \ln (\alpha \beta)+\frac{1}{\beta} \ln (t)
$$

The constants $\alpha$ and $\beta$ were obtained from the slope and intercept of the linear plot of $q_{t}$ versus $\ln t$ [39]. Teng and Hsieh [40] proposed that constant $\alpha$ is related to the rate of chemisorption while $\beta$ is related to the surface coverage. A higher value of $\alpha$ indicates a better adsorption mechanism [41].

The prediction of the rate-limiting step is important in the adsorption processes. It influences design and scale-up of the process. The mechanism of adsorption is generally considered to involve one or any combination of the rate-controlling mechanisms: bulk diffusion, film diffusion, pore diffusion or intra-particle diffusion and chemical adsorption of dye at an active site on the surface. Bulk diffusion is non-limiting when agitation is sufficient to avoid concentration gradients in solution. So, the most important steps are film diffusion, pore diffusion and chemical reaction. Therefore, adsorption diffusion models are mainly constructed to describe the process of film diffusion and/or intra-particle diffusion because the pseudo-first-order and pseudo-second-order models cannot identify the diffusion mechanism $[42,43]$. Weber and Morris [34] described the intra-particle uptake of the adsorption process to be proportional to the half-power of time. The intra-particle diffusion rate constant $\left(k_{i d}\right)$ is given by the following equation:

$$
q_{t}=k_{i d} * \sqrt{ } t
$$

This parameter, although not a reaction rate, can be correlated with system variables to characterise the influence of intra- particle diffusion.

When the boundary plays the most significant role in adsorption during the transport of the solute molecules from the liquid phase up to the solid phase; the liquid film diffusion model may be applied as follows:

$$
\ln (1-F)=-k_{f d} t
$$

Where, $F$ is the fractional attainment of equilibrium $F=q_{t} / q_{e}$ and $k_{f d}$ is the external mass transfer coefficient $\left(1 \mathrm{~min}^{-1}\right)[28,35,41]$.

\section{Error analysis}

Determination of the best isotherm or kinetics model though possible through analysis of the correlation coefficient $\left(R^{2}\right)$, is not sufficient and can lead to some ambiguities when the set of data is not complete. The linearization of isotherm equations using data transformations will implicitly alter the error structure and may also violate the error variance and normality assumptions of standard least squares. Due to the inherent bias from linearization, alternative isotherm parameter sets were determined by non-linear regression. This provides a mathematically meticulous method for determining the isotherm parameters by using the original form of the isotherm equation [24]. In all of the error analysis methods it is assumed that both the liquid-phase concentration and the solid-phase concentration contribute equally to weighting the error criterion for the model solution procedure. In the present study, five error deviation functions were used to predict the optimum isotherm and kinetics model as follows [44]

The Sum of Squared Errors (SSE) (Equation 16) is the most commonly utilized error function. It is assumed that the model which gives the lower SSE values is the best model for dye sorption.

$$
S S E=\sum_{i=1}^{n}\left(q_{e, i, \text { calc }}-q_{e, i, \text { meas }}\right)^{2}
$$

In Sum of absolute errors (SAE) (Equation 17), the approach is similar to the SSE method. Isotherm parameters determined using this error function provides a better fit as the magnitude of the error increases, biasing the fit towards the high concentration data.

$$
S A E=\sum_{i=1}^{n}\left|q_{e, \text { calc }}-q_{e, \text { meas }}\right|_{\mathrm{i}}
$$

The average relative error (ARE) (Equation18) function attempts to minimize the fractional error distribution across the entire concentration range.

$$
A R E=\frac{100}{n} \sum_{i=1}^{n}\left|\frac{q_{e, i, c a l c}-q_{e, \mathrm{i}, \text { meas }}}{q_{e, \mathrm{i}, \text { meas }}}\right|
$$

Hybrid fractional error function (HYBRID) (Equation 19), a composite fractional error function was developed in order to improve the fit of the SAE method at low concentration values [24]. In this method each SAE value is divided by the experimental solid-phase concentration value $q$. In addition a divisor is included as a term for the number of degrees of freedom for the system-the number of data points minus the number of parameters within the isotherm equation.

$$
\text { HYBRID }=\sum_{i=1}^{n}\left[\frac{\left(\mathrm{q}_{e, \text { meas }}-q_{e, \text { cal }}\right)^{2}}{q_{e, \text { meas }}}\right]_{i}
$$

The Marquardt's percent standard deviation (MPSD) (Equation $20)$ is similar in some respects to a geometric mean error distribution modified according to the number of degrees of freedom of the system.

$$
M P S D=\sum_{i=1}^{n}\left[\frac{q_{e, \text { meas }}-q_{e, \text { cal }}}{q_{e, \text { meas }}}\right]_{i}^{2}
$$

Where $q_{\text {ecalc }}$ are the theoretical adsorbed solid phase concentrations of sorbate on sorbent, which have been calculated from one of the isotherm equations and $q_{e, \text { meas }}$ are the experimentally determined adsorbed sorbate concentrations obtained from Equation (1) using the experimentally measured equilibrium sorbate liquid phase concentrations, $C_{e}$.

\section{Desorption and reuse of the biosorbent}

The dye loaded biosorbent prepared by exposing the dried biomass of $R$. arrhizus $(1.2 \mathrm{~g} / \mathrm{L})$ to $\mathrm{RB} 222$ solution $(88 \mathrm{mg} / \mathrm{L})$ at $\mathrm{pH} 1.5$ for 111 min at $35^{\circ} \mathrm{C}$ on a rotary shaker $(80 \mathrm{rpm})$ was used for desorption. The biomass covered with RB 222 was separated by centrifugation at 4000 $\mathrm{rpm}$ for $10 \mathrm{~min}$, washed repeatedly with deionized water to remove any residual dye and dried at $80^{\circ} \mathrm{C}$ for $24 \mathrm{~h}$ before use. The amount of $\mathrm{RB}$ 222 absorbed was calculated to be $72.89 \mathrm{mg} / \mathrm{g}$. Desorption studies were initially optimized using this pre-loaded biosorbent of $R$. arrhizus by using solutions of different molarity $(0.001,0.0015,0.0025,0.005,0.01$, 
0.1 ) of $\mathrm{NaOH}$ as eluant at a constant solid to liquid ratio (S/L) of 10 , in $250 \mathrm{ml}$ Erlenmeyer flasks. The desorption of the dye was optimized over a range of $\mathrm{S} / \mathrm{L}$ of $2,5,8,10,15,20,25,30,40$ and 50 using the molarity of $\mathrm{NaOH}$ that yielded the highest desorption [45]. Each desorption cycle was allowed $120 \mathrm{~min}$ of contact time. The eluted biosorbent was washed repeatedly with deionized water to remove any residual desorbing solution and placed into dye solution for the succeeding biosorption cycle after drying to a constant weight. The cycles were repeated five times using the same biomass.

Desorption efficiency was calculated by using following equation:

$$
\text { Desorption efficiency }=\frac{\text { Amount of dye desorbed }}{\text { Amount of dye adsorbed }} * 100
$$

\section{Results and Discussion}

\section{Characterization of the biosorbent}

XRD analysis: The XRD pattern of $R$. arrhizus revealed poorly resolved peaks indicating a predominance of amorphous nature thereby proving the suitability of the biosorbent for biosorption. The broad peaks obtained at $2 \theta$ were $19.7572,21.4273,24.0244$ and a small sharp peak at $2 \theta$ of 72.6714 with $d$ spacing $4.49365,4.14703,3.70429$ and 1.30113 , respectively [46]. Presence of broad peaks can be attributed to a heterogeneous and complex matrix composed of several substances, including proteins, lipids, carbohydrates, etc. Adsorption of dye may lead to change in molecular and crystalline structure of the adsorbent as was evident from the XRD pattern of the dye laden biosorbent. It exhibited more amorphous character along with appearance of two crystalline peaks at $2 \theta$ of 43.6184 and 51.0984 suggesting that the crystalline dye molecules were adsorbed on the surface mostly by chemisorption causing alteration of the structure of the biosorbent [47].

SEM analysis: Scanning electron microscopy (SEM) has been a primary tool for characterizing the surface morphology and fundamental physical properties of the adsorbent surface. It is useful for determining the particle shape, porosity and appropriate size distribution of the adsorbent $[21,42,48]$. The morphological profile of the biosorbent revealed a rough and heterogeneous surface with relatively porous matrix of macroporous character, pointing towards its potential in taking up the dye. Figure 3 shows the change in the structure of the biosorbent after sorption with RB 222 showing less porous structure indicating effective adsorption of dye molecules in the pores, interstices and cavities on the external surface of this biosorbent. The macropores facilitated easy diffusion of RB 222 into the pores and also assisted adsorption of dye molecules on the surface of the biosorbent.

FTIR analysis: The biosorptive removal of the dyes by the fungal biosorbent is mainly linked to the composition of the cell wall, which is considered as the primary site of bioavalibility [49]. The hexosamineschitin and chitosan constituting approximately $24-40 \%$ of the cell dry weight of Rhizopus along with proteins and lipids serve as a matrix of various functional groups like amine R-NH2 (amino acids, proteins, glycoproteins, etc.), carboxylic (fatty acids, lipopolysaccharides, etc.), which take part in binding of dye ions [50]. A closer insight into the biomass surface properties was obtained by comparing the FTIR spectra of biomass of R. arrhizus, before and after biosorption with RB 222 in the range of $400-4000 \mathrm{~cm}^{-1}$. The infrared spectrum of the biosorbent displayed the complex and heterogeneous nature showing characteristic bands of proteins, lipids and polymeric compounds. Despite the complexity, certain typical characteristic peaks could be assigned to functional groups [51].
Peaks between 3500 to $3200 \mathrm{~cm}^{-1}$ represent-OH groups of alcohols and phenols and primary, secondary amines or amide $-\mathrm{N}-\mathrm{H}$ groups, while peaks between 3300 to $2500 \mathrm{~cm}^{-1}$ indicate $\mathrm{O}-\mathrm{H}$ stretch of carboxylic acids [52]. Peak positions between the wave number ranges of $2000 \mathrm{~cm}^{-1}$ to $500 \mathrm{~cm}^{-1}$, indicate the vibrational modes that are specific to the type of polysaccharides and glycosidic linkages and denote the presence of aldehyde groups which are actively involved in biosorption. Amide I bands $\left(1700-1600 \mathrm{~cm}^{-1}\right)$ due to $\mathrm{C}=\mathrm{O}$ stretching vibrations of peptide bond provide insight into the protein secondary structure. Peaks between $910-665 \mathrm{~cm}^{-1}$ represent N-H wag of primary and secondary amines. The FTIR spectra of the biosorbent exhibited appearance, disappearance and shifting of various peaks with change in intensity due to change in bonding energy in the corresponding functional groups after biosorption. This confirmed changes in the availability of the functional groups and active role played by them in biosorption (Figures 5-8).

Peaks at $3523.95-3302.13 \mathrm{~cm}^{-1}$ indicate the presence of carboxyl, primary and secondary amines and amides. Disappearance of peaks at $3523.95,3302.13 \mathrm{~cm}^{-1}$ indicates their involvement. The spectrum displayed the absorption peaks at $1743.65,1710.86$, and $1238.3 \mathrm{~cm}^{-1}$, corresponding to carboxyl groups. Shifts in peaks corresponding to carboxylic groups (1238.3 to $1228.66 \mathrm{~cm}^{-1}$ ) and disappearance of peaks at 1743.65 and $1710.86 \mathrm{~cm}^{-1}$ indicates their participation. Disappearance of peaks at $3226.91 \mathrm{~cm}^{-1}$ and shifting of peak at 1539.2 to $1543.05 \mathrm{~cm}^{-1}$ indicated the contribution of amine groups in the binding of RB 222. Disappearance of peak at $1031.92 \mathrm{~cm}^{-1}$ and shifting of bands from 3282.84 to $3294.42 \mathrm{~cm}^{-1} ; 2852.72$ to $2854.65 \mathrm{~cm}^{-1}$ and 1159.22 to $1161.15 \mathrm{~cm}^{-1}$ indicated the involvement by $\mathrm{C}-\mathrm{O}$ stretching vibrations, $\mathrm{NH}$ bending, $\mathrm{C}-\mathrm{O}-\mathrm{C}$ linkage, bonded hydroxyl $\mathrm{OH}$ of water in binding of the dye when compared to that of the biomass of $R$. arrhizus before biosorption. Several bands in the range of $1658.78-1379.10 \mathrm{~cm}^{-1}$ are assigned to phenolic and amine groups. The disappearance of peak at $1379.10 \mathrm{~cm}^{-1}$ after binding of RB 222 indicated their participation in the biosorption. The peaks at $2924.09 \mathrm{~cm}^{-1}$ can be attributed to asymmetric $\mathrm{C}-\mathrm{H}$ stretching vibrations of methyl, methylene and methoxy groups did not change even after biosorption with RB 222, indicating that these groups did not participate in in the biosorption process [53-55]. FTIR technique proved to be an efficient tool for detecting structural changes and probable binding sites induced by the biosorption of RB 222 .

Modification of the functional groups: The potential functional groups implicated in biosorption by FTIR analysis, were blocked by chemical treatments to study the extent of their involvement by measuring the percent reduction in the biosorption. The treatment of the biosorbent with formic acid ( $\mathrm{HCHO}-\mathrm{HCOOH})$ causes blocking of primary and secondary amines on the biosorbent due to their methylation [19]. The reaction occurs as follows:

$$
\mathrm{RCH}_{2} \mathrm{NH}_{2} \stackrel{\text { нсноннсоон }}{\longrightarrow} \mathrm{RCH} \mathrm{CH}_{2}\left(\mathrm{CH}_{3}\right)_{2}+\mathrm{CO}_{2}+\mathrm{H}_{2} \mathrm{O}
$$

The methylation of the positively charged amino groups strongly affected the removal of RB 222 by $R$. arrhizus showing a significant reduction of $57.29 \%$ in biosorption. This reduction can be attributed to prevention of their participation in dye biosorption, indicating a major role played by them in biosorption of RB222. Chitin carries one linear amino group per glucose unit and thus exhibits a high dye uptake capacity [54].

Treatment of the biosorbent with ethanol results in esterification of carboxylic acids causing reduction in the number of positively charged sites present on the cell wall of the biosorbent and the reaction occurs as follows [19]: 


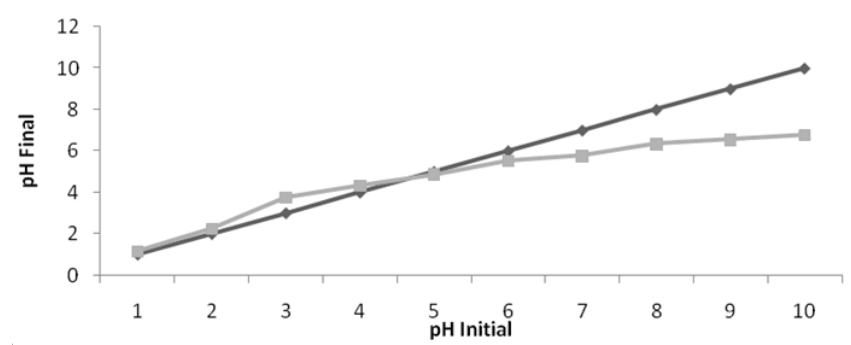

Figure 5: Plot of initial versus final $\mathrm{pH}$ for the determination of $\mathrm{pHzpc}$ of $R$. arrhizus biomass.

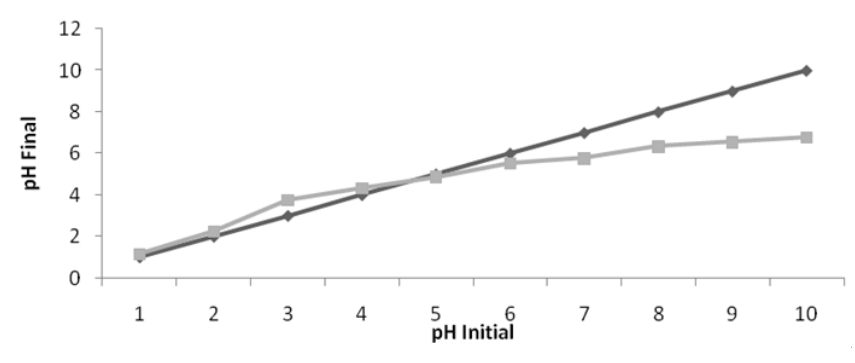

Figure 6: Intra-particle diffusion model.

$$
\mathrm{RCOOH}+\mathrm{CH}_{3} \mathrm{OH} \stackrel{\mathrm{H}^{+}}{\longrightarrow} \mathrm{RCOOCH}_{3}+\mathrm{H}_{2} \mathrm{O}
$$

Esterification of the carboxyl groups decreased the biosorption of RB 222 by $8.61 \%$ indicating that carboxylic groups also to some extent contributed to biosorption of RB 222. Thus, it can be inferred from the above results that amines and the carboxyl groups of chitin do play a role in the sorption of RB 222. However, the role of carboxylic acids is minor to that of amines. Since RB 222 has only one $\mathrm{NH}_{2}$ group in the dye molecule, interactions between carboxyl and carbonyl groups of the biosorbents and $\mathrm{NH}_{2}$ group of the dyes maybe less important than that of $\mathrm{NH}_{2}$ groups of biosorbent and $\mathrm{SO}_{2}^{-3}$ groups of the dye [56].

Removal of lipids from the biosorbent also exhibited a negative effect causing $4.44 \%$ reduction in the biosorption of RB 222, which revealed the contribution of lipids present on the cell wall of $R$. arrhizus in biosorption. The reduction in biosorption can be attributed to possible structural changes that may have occurred due to the harsh condition employed for the extraction process [57].

Determination of zero point of charge $\left(\mathrm{pH}_{\mathrm{zpc}}\right)$ : The $\mathrm{pH}$ of the dye solution affects surface functionality and thus plays a vital role in the adsorption process and particularly affects the adsorption capacity. A convenient index of the propensity of a surface to become either positively or negatively charged as a function of $\mathrm{pH}$ is the value of the $\mathrm{pH}$ required to give zero net surface charge, called point of zero charge $\left(\mathrm{pH}_{\mathrm{ZPC}}\right)$ [58]. This indicates that the surface has a negative surface charge above the $\mathrm{pH}_{\mathrm{ZPC}}$ and a positive surface charge below the $\mathrm{pH}_{\mathrm{ZPC}}$ [59]. The R. arrhizus biosorbent used in this study has the $\mathrm{pH}_{\mathrm{ZPC}}$ value of 4.88. This means that at $\mathrm{pH}$ higher than 4.88 the surface bears a negative charge, while at $\mathrm{pH}$ below 4.88 the surface functional groups, such as amino and carboxyl groups are positively charged providing cationic anchor points with which the dye anions can interact [26].

\section{Isotherm studies}

An equilibrium analysis is the most important fundamental information required for evaluation of the affinity of a sorbent as well as the applicability of sorption process as a unit operation. The shape of an isotherm can provide qualitative information on the nature of the solute-surface interaction and predict if a sorption system is favourable or unfavourable [60]. Isotherm curve for the biosorption of RB 222 by $R$. arrhizus showed concave shape and a plateau which is characteristic of the L2-type curve according to the Giles and Smith classification [61].

The L2-type isotherms indicate adsorption of the solute on the adsorbent until the formation of a monolayer without the existence of strong competition between the adsorbate and the solvent to occupy the adsorption sites. The formation of more than one layer is not possible due to the electrostatic repulsion between adsorbed dyes molecules and those in solution [29,61]. Since biosorption isotherm curve of RB 222 was of L2-type, four widely used mono-component isotherm models were employed (Table 1).

The essential characteristics of the Langmuir isotherm, expressed in terms of a dimensionless constant separation factor or equilibrium parameter, $R_{L}$, indicates the nature of adsorption to be either unfavourable $\left(R_{L}>1\right)$, linear $\left(R_{L}=1\right)$, favourable $\left(0<R_{L}<1\right)$ or irreversible $\left(R_{L}=0\right)$ [62]. The low $R_{L}$ value $(0.003)$ in the present investigation indicated that the adsorption of RB222 onto the biosrbent is favorable. A high value of Langmuir parameter $q_{\text {calc }}$ predicts the monolayer biosorption capacity of the biomass and is suggestive of high biosorption capacity. The second Langmuir parameter $K_{L}$ reflects the affinity of a sorbent for a particular dye ion. Langmuir isotherm model fitted the results reasonably well $\left(\mathrm{R}^{2}=0.999\right)$, suggesting that the surface of the sorbent could be homogenous and attainment of saturation during dye biosorption was achieved. It also indicated that the sorbed molecules are organized as a reversible monolayer, all sites are energetically equivalent and there is no interaction between the sorbed molecules

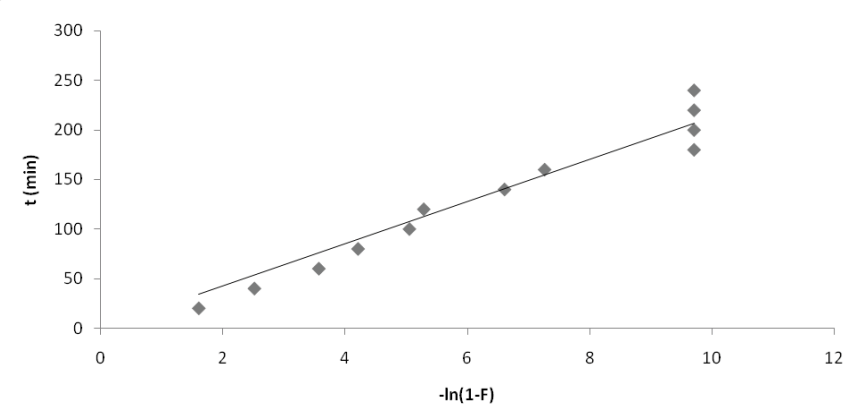

Figure 7: Liquid film diffusion.

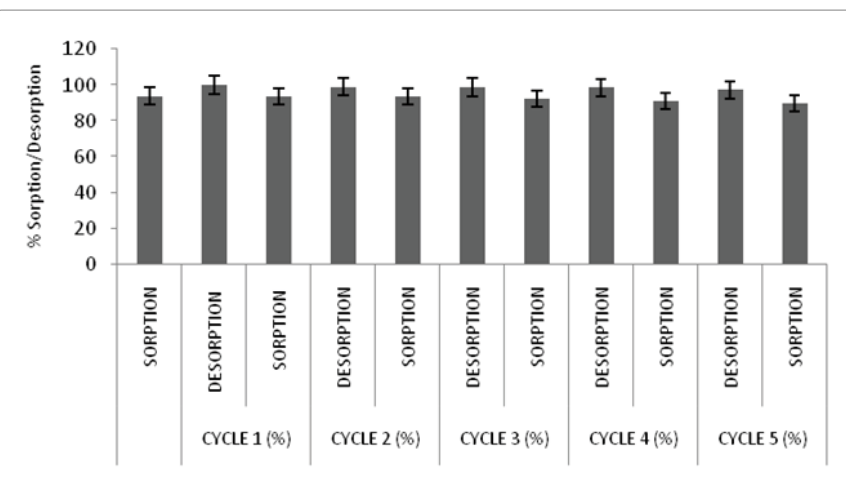

Figure 8: Quantity of Reactive Blue 222 dye adsorbed and desorbed in sorption/deorption cycles. 


\begin{tabular}{|c|c|c|c|c|c|c|c|}
\hline \multicolumn{2}{|c|}{ Langmuir } & \multicolumn{2}{|c|}{ Freundlich } & \multicolumn{2}{|c|}{ Temkin } & \multicolumn{2}{|c|}{ Dubinin-Radushkovich } \\
\hline$q_{e^{\prime} \exp }(\mathrm{mg} / \mathrm{g})$ & 72.94 & $q_{e^{\prime} \text { exp }}(\mathrm{mg} / \mathrm{g})$ & 72.94 & $q_{e^{\prime} \text { exp }}(\mathrm{mg} / \mathrm{g})$ & 72.94 & $q_{e^{\prime} \text { exp }}(\mathrm{mg} / \mathrm{g})$ & 72.94 \\
\hline$q_{e^{\prime} \text { cal }}(\mathrm{mg} / \mathrm{g})$ & 72.88 & $q_{e}{ }_{c a l}(\mathrm{mg} / \mathrm{g})$ & 72.58 & $q_{e^{\prime} \text { cal }}(\mathrm{mg} / \mathrm{g})$ & 72.51 & $q_{e^{\prime} \text { cal }}(\mathrm{mg} / \mathrm{g})$ & 79.06 \\
\hline$K_{L}(\mathrm{~L} / \mathrm{mg})$ & 3.4 & $K_{F}$ & 74.664 & $B(\mathrm{~J} / \mathrm{mol})$ & 6.06 & $B_{D}(\mathrm{mg} / \mathrm{g})$ & $1 * 10^{-07}$ \\
\hline \multirow[t]{2}{*}{$R_{L}$} & 0.003 & $n$ & 10.869 & $A_{T}(\mathrm{~L} / \mathrm{g})$ & $2.16^{*} 10^{05}$ & $E(\mathrm{KJ} / \mathrm{mol})$ & 2.236 \\
\hline & & & & $b$ & 0.4227 & & \\
\hline$R^{2}$ & 0.999 & & 0.979 & & 0.974 & & 0.966 \\
\hline SSE & $3.6^{*} 10^{-03}$ & & 0.1296 & & 0.1849 & & 37.45 \\
\hline SAE & $06^{*} 10^{-02}$ & & 0.36 & & 0.43 & & 6.12 \\
\hline ARE & $8.22 * 10^{-02}$ & & 0.4935 & & 0.5895 & & 8.39 \\
\hline HYBRID & $4.93^{*} 10^{-05}$ & & $1.70^{*} 10^{-03}$ & & $2.5^{*} 10^{-03}$ & & 0.51 \\
\hline MPSD & $6.76^{*} 10^{-07}$ & & $2.44^{*} 10^{-05}$ & & $3.47^{*} 10^{-05}$ & & $7.00 * 10^{-03}$ \\
\hline
\end{tabular}

Table 1: Isotherm parameters and error analysis for adsorption of RB 222 on $R$. arrhizus.

[63]. However, biosorption sites on the fungi are not homogeneous, as presumed in the Langmuir model, because they contain functional groups of diverse kind, which vary in their affinity for dye ions.

The Freundlich isotherm model for sorption of RB 222 also fitted well yielding a straight line. The values of $1 / n$ and $K_{F}$ were calculated from the slope and intercept of the plot of $\ln q_{e}$ versus $\ln C_{e}$. The $K_{F}$ is found to be primarily related to the capacity of the adsorbent for the given ion; the higher the value of $K_{F}$ the larger is the capacity of sorption. A very high value of $K_{F}$ (74.66) compared favourably with other adsorbents used for the sorption of RB 222 by other researchers viz. 22.6-43.6 mg/g for chitosan [64]; industrial solid waste included Al (III) hydroxide $5.83 \mathrm{mg} / \mathrm{g}$ [65]. Freundlich isotherm constant $1 / n$ can be used to calculate the adsorption capacity and intensity of the reaction and to explore the favourability of adsorption process. The slope $1 / n$ value indicates the type of isotherm to be irreversible $(1 / n=0)$, favorable $(0<1 /$ $n<1)$, unfavorable $(1 / n>1)$. A value of $1 / n=1$ shows that the partition between two phases does not depend on the concentration, while $1 / n>1$ indicates a cooperative sorption involving strong interactions between the molecules of adsorbate. The slope of 0.092 suggested that the adsorption is heterogenous. Isotherms with value of $1 / n$ below unity are classified as L-type isotherms reflecting a high affinity between adsorbate and adsorbent and are indicative of chemisorption whereas $1 / n$ above one is an indication of cooperative adsorption. In the present investigation values of slope below one indicated chemisorption [62]. Conformity to the Freundlich model indicated that the biomass was completely saturated and the dye ions were adsorbed reversibly onto the surface in a multilayered pattern [66]. The regression coefficient $\left(R^{2}\right)$ value (0.979) for RB 222, was lower compared to Langmuir model, which can be attributed to assumption of the Freundlich model that dye biosorption does not saturate. However, isotherm curve of RB 222 clearly depicted saturation of dye ions. Thus, the Freundlich model is less appropriate than Langmuir model for defining dye biosorption by the biosorbent, even though its parameters do convey some important information regarding dye biosorption and intensity [29].

Linear plot for Temkin adsorption isotherm, which considers monolayer chemisorption of an adsorbate onto the adsorbent, fitted quite well $\left(R^{2}=0.97\right)$. This further supports the findings that the adsorption of RB 222 onto the biosorbent occurs by a chemisorption process. The $\mathrm{D}-\mathrm{R}$ isotherm model is more general than the Langmuir isotherm as its deviations are not based on ideal assumptions such as equipotential of sorption sites, absence of steric hindrances between sorbed and incoming particles and surface homogeneity on microscopic level. In the present study, the estimated constant, $B_{D^{\prime}}$ related to adsorption energy was $1^{\star} 10^{-7} \mathrm{mg} / \mathrm{g}$. This constant gives an idea about the mean free energy which was valued as $E=2.236 \mathrm{~kJ} / \mathrm{mol}$.
$E$ is a parameter used in predicting the type of adsorption. Based on this energy of activation one can predict whether an adsorption is physisorption or chemisorption [30]. However, deviation from the measured SUC of the biosorbent for RB 222 showed that D- R isotherm model did not give very good description of the sorption process. Thus, it can be assumed that the sorption takes place by chemisorption as suggested by Langmuir, Freundlich and Temkin isotherms though the data were described well by the Langmuir model based on the error analysis (Tables 1 and 2).

\section{Kinetic studies}

It has been reported that the Lagergren's model does not fit the kinetic data well for the entire range of contact time and is generally applicable over the initial 20-30 min of the sorption process and results generally show highly varied $q_{e}$ values as seen in this study [15]. The reason for this difference in the $q_{e}$ value is that there is a time lag at the beginning of the sorption process, possibly due to a boundary layer or external resistance control [32]. Thus, the adsorption of RB 222 on the biosorbent did not follow the pseudo-first order adsorption kinetics.

On the other hand, a correlation coefficient $\left(R^{2}\right)$ of 0.999 and the closeness of the experimental equilibrium capacity $q_{\text {eqexp }}$ estimated from the pseudo-second order kinetics with theoretical $q_{\text {eq }}$ value indicated a good compliance with the pseudo second-order model, based on the assumption that the rate limiting step may be chemisorption [67].The biosorption data were further analyzed using the Elovich equation. It has extensively been accepted that the chemisorption process can be described by this semi-empirical equation [68]. Teng and Hsieh [40] proposed that constant $\alpha$ is related to the rate of chemisorption while $\beta$ is related to the surface coverage. The constants depend significantly on the amount of adsorbent with the adsorption constant, $\alpha$, being a more sensitive parameter. A good biosorption process is indicated by a higher value of $\alpha$, as seen in this case (1613.56). The correlation coefficients of Elovich equation (0.889), was lower than those of the pseudo secondorder equation.

The relatively short contact time, necessary for achieving equilibrium conditions (less than three hours as seen in this study), apart from the evident processing advantages, is considered as an initial indication that adsorption of dyes on R. arrhizus is chemicalreaction controlled, rather than a diffusion controlled process [15]. A more appropriate quantitative approach to distinguish between kinetic and diffusion rate control is to perform the square root of contact time analysis. The plot of $q_{t}$ versus $t^{0.5}$ (Figure 6), presents multi-linearity implying that more than one process affected the adsorption, which was also shown in previous studies $[16,60,64]$. The first, sharper portion was attributed to an instantaneous adsorption stage of diffusion of dyes 


\begin{tabular}{|c|c|c|c|c|c|c|c|c|c|}
\hline \multicolumn{2}{|c|}{ First Order } & \multicolumn{2}{|c|}{ Second Order } & \multicolumn{2}{|c|}{ Elovich } & \multicolumn{2}{|c|}{ Intra particle } & \multicolumn{2}{|c|}{ Liquid film diffusion } \\
\hline$q_{e^{\prime} \text { exp }}(\mathrm{mg} / \mathrm{g})$ & 72.94 & $q_{e^{\prime} \text { exp }}(\mathrm{mg} / \mathrm{g})$ & 72.94 & $q_{e^{\prime} \exp }(\mathrm{mg} / \mathrm{g})$ & 72.94 & $q_{e^{\prime} \text { exp }}(\mathrm{mg} / \mathrm{g})$ & 72.94 & $q_{e^{\prime} \text { exp }}(\mathrm{mg} / \mathrm{g})$ & 72.94 \\
\hline$q_{\text {ecalc }}(\mathrm{mg} / \mathrm{g})$ & 1.36 & $q_{\text {ecalc }}(\mathrm{mg} / \mathrm{g})$ & 73.55 & $q_{\text {ecalc }}(\mathrm{mg} / \mathrm{g})$ & 94.29 & $q_{\text {ecalc }}(\mathrm{mg} / \mathrm{g})$ & 79.25 & $q_{\text {ecalc }}(\mathrm{mg} / \mathrm{g})$ & 75.35 \\
\hline \multirow[t]{2}{*}{$k_{1}\left(\min ^{-1}\right)$} & 0.016 & $k_{2}\left(\mathrm{gmg}^{-1} \mathrm{~min}^{-1}\right)$ & 0.3647 & $\alpha(\mathrm{mg} / \mathrm{gmin})$ & 1613.56 & $k_{i d}\left(\mathrm{mg} /\left(\mathrm{g} \mathrm{min} \min ^{1 / 2}\right)\right)$ & 3.053 & $F$ & 1.00 \\
\hline & & & & $\beta(\mathrm{g} / \mathrm{mg})$ & 0.138 & $C(\mathrm{mg} / \mathrm{g})$ & 46.09 & $k_{f d}(\mathrm{~L} / \mathrm{min})$ & 0.053 \\
\hline$R^{2}$ & 0.988 & & 0.999 & & 0.889 & & 0.926 & & 0.948 \\
\hline SSE & 5123.7 & & 0.37 & & 455.82 & & 39.82 & & 5.81 \\
\hline SAE & 71.58 & & 0.61 & & 21.35 & & 6.31 & & 2.41 \\
\hline ARE & 98.13 & & 0.836 & & 29.271 & & 8.651 & & 3.304 \\
\hline HYBRID & 70.24 & & 0.005 & & 6.249 & & 0.546 & & 0.08 \\
\hline MPSD & 0.963 & & $1 * 10^{-04}$ & & 0.086 & & $7^{*} 10^{-03}$ & & $1 * 10^{-03}$ \\
\hline
\end{tabular}

Table 2: Kinetics parameters and error analysis for adsorption of RB 222 on R. arrhizus.

through the solution to the external surface of the biosorbent, or the boundary layer diffusion effect (i.e., external film resistance) of solute molecules. The second portion described the gradual adsorption stage of intra-particle diffusion (macro- and meso-pore diffusion). The third portion was attributed to the final equilibrium stage where the dye is adsorbed on sites on the interior surface of the biosorbent. This stage is assumed to occur very rapidly and does not form a rate-limiting stage in the adsorption of dyes onto the biosorbent. The intra-particle diffusion also starts to slow down due to the extremely low dye concentration left in the solution. The rate of uptake might be limited by the size of adsorbate molecule, concentration of the adsorbate and its affinity to the adsorbent, the pore-size distribution of the adsorbent, etc. [44].

The rate constant $k_{i d}\left(\mathrm{mgg}^{-1} \mathrm{~min}^{-0.5}\right)$ of the intra-particular diffusion on the biosorbent was low probably indicating slow diffusion of the bulky molecule of RB 222 during the adsorption process. Jadhav and Vanjara [69] reported slow rate of sorption in case of big molecules such as acidic, basic and disperse dyes on sawdust, polymerized sawdust and sawdust carbon. According to Weber and Morris [34], if intra-particle diffusion is involved in the adsorption process, then the plot of the square root of time versus the uptake would result in a linear relationship and intra-particle diffusion would be the rate-limiting step if this line passed through the origin. The deviation of the straight line from the origin is indicative of some degree of boundary layer control and further shows that the intra-particle diffusion is not the only rate controlling step, but that other processes may control the rate of adsorption $[60,68]$. The extrapolation of the linear straight line to the time axis gives intercepts $C$, which is proportional to the boundary layer thickness. This is attributed to the instantaneous utilization of the most readily available adsorbing sites on the adsorbent surface [60]. In the present study, a very large value of $C$ suggests a greater boundary layer effect and greater contribution of the surface adsorption in the rate limiting step [70].

The linear plot of $-\ln (1-F)$ vs. $t$ whereby $F=q_{t} / q_{e}$, despite providing good linearity does not pass through the origin (Figure 7). Thus, it can be concluded that liquid film diffusion is not the predominant mechanism for RB 222 adsorption on the biosorbent. Error analysis revealed that the second order kinetic model best described the biosorption of RB 222 on the biosorbent.

\section{Desorption and reuse of the biosorbent}

One of the key factors in assessing its potential for commercial application is the regeneration of the biosorbent. Desorption studies not only help to elucidate the nature of adsorption, they are also critical in keeping the costs down while recovering the dye non-destructively from the liquid phase in a concentrated form, facilitating its disposal and thus restoring the biosorbent for effective reuse. The stability and the potential reusability of the biosorbent were assessed by monitoring the change in recovery through five consecutive adsorption- desorption cycles of 200 min each.

As the molarity of $\mathrm{NaOH}$ increased ( $\mathrm{S} / \mathrm{L}$ at 10 ) from $0.001 \mathrm{M}$ to $0.01 \mathrm{M}$, the percent desorption increased from 2.18 to $96.22 \%$. This can be attributed to the increase in negative $\mathrm{OH}$-ions creating a negatively charged surface on the biosorbent which favoured the desorption of dye anions due to the electrostatic repulsion [71]. Use of $1 \mathrm{M} \mathrm{NaOH}$ reduced the desorption of RB 222 similar to the trend reported by Arami et al. [71], Kadirvelu et al. [72] and Patel and Sumathi [73] during desorption of dyes from orange peel, activated carbon and Aspergillus foetidus, respectively.

The efficiency of the desorbing agent is often expressed by the solid to liquid ratio (S/L). High values of $\mathrm{S} / \mathrm{L}$ are desirable for complete elution and to make the process more economical [74]. However, at the same time, the volume of the solution should be enough to provide maximum solubility for the desorbed dye. Hence, using $0.1 \mathrm{M} \mathrm{NaOH}$ as an eluant, $\mathrm{S} / \mathrm{L}$ was optimized from 2 to 50 .The desorption increased with increase in S/L from 2 to 10 yielding highest value $(98.51 \%)$ at $\mathrm{S} / \mathrm{L}$ of 10, decreasing thereafter (Figure 7). The biosorbent undergoing successive adsorption-desorption processes retained good adsorption capacity even after five cycles and only a maximum of $1.26 \%$ decrease in sorption capacity was observed after five cycles.

\section{Mechanism of biosorption}

The determination of the adsorption mechanism is important for design purposes. The adsorption mechanism often depends on the chemical composition of the adsorbent, the nature of adsorbate and the solution environment. The fitting of the experimental data to both Langmuir and Freundlich isotherm models suggested that the biosorption process was a monolayer capacitive sorption process in which homogeneous and heterogeneous biosorption patches coexisted on the surface of $R$. arrhizus and the biosorption process involved more than one mechanism. The goodness of fit provided by pseudo second-order equation suggested that the rate limiting step may be chemisorption. FTIR analysis and modification of amino groups indicated a dominant sorption mechanism involving electrostatic interaction of the anionic groups of RB 222 with protonated amine/ imine groups of the biosorbent [67]. Binding of RB 222 to R. arrhizus can be attributed to electrostatic interactions between six $\mathrm{SO}_{3}^{-2}$ groups on the dye and positively charged amine sites in the biomass [54]. Simultaneously, weak interactions between the sorbent matrix and numerous benzene rings in the dye molecule, as well as hydrogen bonding, could play an important role. The availability of amine groups is controlled by two important parameters: the crystallinity of the polymer and the diffusion properties. Predominance of amorphous 
Citation: Saraf S, Vaidya VK (2016) Elucidation of Sorption Mechanism of R. arrhizus for Reactive Blue 222 using Equilibrium and Kinetic Studies. J Microb Biochem Technol 8: 236-246. doi: 10.4172/1948-5948.1000292

nature revealed by the XRD analysis indicated the accessibility of adsorption sites and thus the suitability of the biosorbent for biosorption. Overall, the sorption process can be described as follows: RB 222 is first adsorbed on the surface of $R$. arrhizus by chemisorption via electrostatic interaction until the surface functional sites are fully occupied; thereafter dye molecules diffuse into the pores of the biosorbent layers for further interactions [39,42]. A greater boundary layer effect shown by intra-particle diffusion model suggested a greater contribution of the surface adsorption in the rate limiting step. Similar results were reported by Uzun [75].

\section{Conclusion}

R. arrhizus, a low cost waste biomass from industrial fermentations proved to be a promising biosorbent due to a short equilibrium time and high specific uptake capacity. The XRD pattern of $R$. arrhizus revealed preponderance of amorphous nature thereby proving the suitability of the biosorbent for biosorption. The heterogeneous surface with relatively porous profile of the biosorbent was revealed by SEM analysis. Langmuir, Freundlich and Temkin models fitted the adsorption equilibrium data with high correlation coefficients, though the Langmuir model described the data most efficiently. The suitability of the pseudo-second order equation for the sorption of RB 222 pointed towards chemisorption as the mechanism of biosorption. The experimental data also showed that intra-particle diffusion plays a significant role in determination of the sorption rate. FTIR analysis and modification of functional groups showed contribution of amino and carboxyl groups in biosorption. Desorption and reusability studies using $0.1 \mathrm{M} \mathrm{NaOH}$ as eluant at $\mathrm{S} / \mathrm{L}$ of 10 , showed potential for the recovery and the further containment of RB 222. The biosorbent could be regenerated and reused at least five times in biosorption-desorption cycles successively.

\section{References}

1. Asamudo NU, Daba AS, Ezeronye OU (2005) Bioremediation of textile effluent using Phanerochaete chrysosporium. Afr J Biotechnol 4: 1548-1553.

2. Mathur N, Bhatnagar P, Bakre $P(2005)$ Assessing mutagenicity of textile dyes from Pali (Rajasthan) using Ame's bioassay. Appl Ecol Environ Res 4: 111-118.

3. Allègre $C$, Moulin $P$, Maisseu M, Charbit $F(2006)$ Treatment and reuse of reactive dyeing effluents. J Membr Sci 269: 15-34.

4. Aravind UK, George B, Baburaj MS, Thomas S, Thomas AP, et al. (2010) Treatment of industrial effluents using polyelectrolyte membranes. Desalination 252: 27-32.

5. Mathur N, Bhatnagar $P(2007)$ Mutagenicity assessment of textile dyes from Sanganer (Rajasthan). J Environ Biol 28: 123-126.

6. ZilleA (2005) Laccase reactions for textile applications. Ph D thesis, Universidadedo Minho, Portugal.

7. Murugesan K (2003) Bioremediation of paper and pulp mill effluents. Indian $J$ Exp Biol 41: 1239-1248.

8. Skult F (2009) The biosorption behavior of inactive Aspergillus niger modified by autoclaving in treating dye wastewater. Undergraduate Student Research Program, Lund University.

9. RussoME, MarzocchellaA, OlivieriG, PrigioneV, SalatinoP, et al. (2009) Characterization of dyes biosorption on fungal biomass. In: Pierucci, 9th International Conference on Chemical and Process Engineering AIDIC, Milano.

10. ErdenE, Kaymaz Y, PazarliogluNK (2011) Biosorption kinetics of a direct azo dye Sirius Blue K-CFN by Trametes versicolor. Electron J Biotechnol 14: 8-11.

11. SulaymonAH, EbrahimSE, AbdullaSM, Al-MusawiTJ (2010) Removal of lead, cadmium and mercury ions using biosorption. Desalin Water Treat 24: 344-352.

12. Sulaymon AH (2013) Competitive biosorption of lead mercury chromium and arsenic ions onto activated sludge in batch adsorber. Aquat Sci Technol1: 30-51.
13. SagY, AktayY (2002) Kinetic studies on sorption of $\mathrm{Cr}(\mathrm{VI})$ and $\mathrm{Cu}(\mathrm{II})$ ions by chitin, chitosan and Rhizopus arrhizus. Biochem Eng J 12: 143-153.

14. Ambrósio ST, José C, Vilar J, Carlos A, Alves S, et al. (2012) A Biosorption isotherm model for the removal of reactive azo dyes by inactivated mycelia of Cunninghamella elegans UCP542. Molecules 17: 452-462.

15. Ho YS, McKay G (2000) Correlative biosorption equilibria model for a binary batch system. Chem Eng Sci 55: 817-825.

16. Foo KY, Hameed BH (2010) Insights into the modeling of adsorption isotherm systems. Chem Eng J 156: 2-10.

17. Saraf S, Vaidya VK (2015) Statistical optimization of biosorption of Reactive Orange 13 by dead biosorbent of Rhizopus arrhizus NCIM 997 using response surface methodology. Int J Ind Chem 6: 93-104.

18. Kapoor A, Viraraghavan T (1997) Heavy metal biosorption sites in Aspergillus niger. Biores Technol 61: 221-227.

19. Parvathi K, Nagendran R, Nareshkumar R (2007) Lead biosorption onto waste beer yeast by-product, a means to decontaminate effluent generated from battery manufacturing industry. Electron J Biotechnol 10: 92-105.

20. Hasan SH, Ranjan D, Talat M (2010) Water hyacinth biomass (WHB) for the biosorption of hexavalent chromium: Optimization of process parameters. Bioresour 5: 563-575.

21. Akar ST, Akar T, Çabuk A (2009) Decolorization of a textile dye, Reactive Red 198 (RR198), by Aspergillus parasiticus fungal biosorbent. Braz J Chem Eng 26: $399-405$

22. Thompson G, Swain J, Kay M, Forster CF (2001) The treatment of pulp and paper mill effluent: A review. Bioresour Technol 77: 275-286.

23. El-Khaiary MI (2008) Least-squares regression of adsorption equilibrium data Comparing the options. J Hazard Mater 158: 73-87.

24. Brdar MM, TakaciAA, Šciban MB, Rakic DZ (2012) Isotherms for the adsorption of $\mathrm{Cu}(\mathrm{II})$ onto lignin - comparison of linear and non-linear methods. Hem Ind 66: 497-503.

25. Piccin JS, Dotto GL, Pinto LAA (2011)Adsorption isotherms and thermochemical data of FD \& C Red N 40 binding by chitosan. Braz J Chem Eng 28: 295-304.

26. Aksu Z, Dönmez G (2003)A comparative study on the biosorption characteristics of some yeasts for Remazol Blue reactive dye. Chemosphere 50: 1075-1083.

27. Tempkin MI, Pyzhev V (1940) Kinetics of ammonia synthesis on promoted iron catalyst. Acta Phys Chim USSR 12: 327-356.

28. Oladoja NA, Aboluwoye CO, Oladimeji YB (2008) Kinetics and isotherm studies on Methylene Blue adsorption onto ground palm kernel coat. Turk J Eng Env Sci 32: 303-312.

29. Kumar D, Pandey LK, Gaur JP (2010) Evaluation of various isotherm models, and metal sorption potential of cyanobacterial mats in single and multi-metal systems. Colloids Surf B Biointerfaces 81: 476-485.

30. ItodoAU, ItodoHU (2010) Sorption energies estimation using DubininRadushkevich and Temkin adsorption isotherms. Life Sci J 7: 31-39.

31. Ho YS (2004) Citation review of Lagergren kinetic rate equation on adsorption reactions. Scientometrics 59: 171-177.

32. Mc Kay G, HoYS, Ng JCY (1999) Biosorption of copper from wastewaters: A review. Sep Purif Meth 28: 87-125.

33. Ho YS, Mc Kay G (1998) A kinetic study of dye sorption by biosorbent waste product pith. Resour Conserv Recy 25: 171-193.

34. Weber WJ, Morris JC (1963) Kinetics of adsorption on carbon from solution. J Sanit Eng Div ASCE 89: 31-59.

35. Boyd GE, Adamson AW, Myers LS (1947) The exchange adsorption of ions from aqueous solutions by organic zeolites (II) kinetics. J Am Chem Soc 69: 2836-2848.

36. Lagergren S (1898) About the theory of so- called adsorption of soluble substances. Kunglia Svenska Vetenskapsakademiens Handlingar, Band 24 $1-39$.

37. BayramoÄŸlu G, Celik G, Arica MY (2006) Biosorption of Reactive Blue 4 dye by native and treated fungus Phanerocheate chrysosporium: Batch and continuous flow system studies. J Hazard Mater 137: 1689-1697. 
Citation: Saraf S, Vaidya VK (2016) Elucidation of Sorption Mechanism of R. arrhizus for Reactive Blue 222 using Equilibrium and Kinetic Studies. J Microb Biochem Technol 8: 236-246. doi: 10.4172/1948-5948.1000292

38. Ho YS, Porter JF, Mc Kay G (2002) Equilibrium isotherm studies for the sorption of divalent metal ions onto peat: Copper, nickel and lead single component systems. Water Air Soil Pollut 141: 1-33.

39. Bulut E, Ozacar M, Sengil IA (2008) Equilibrium and kinetic data and process design for adsorption of Congo Red onto bentonite. J Hazard Mater 154: 613622.

40. Teng $\mathrm{H}$, Hsieh $\mathrm{C}$ (1999) Activation energy for oxygen chemisorption on carbon at low temperatures. Ind Eng Chem Res 38: 292-297.

41. Aroua MK, Leong SP, Teo LY, Yin CY, Daud WM (2008) Real-time determination of kinetics of adsorption of lead(II) onto palm shell-based activated carbon using ion selective electrode. Bioresour Technol 99: 5786-5792.

42. Altaher H, Khalil TE, Abubeah R (2014) The effect of dye chemical structure on adsorption on activated carbon: A comparative study.

43. Qui H, Lv L, PanB C, Zhang QJ, Zhang WM, et al. (2009) Critical review in adsorption kinetic models. J Zhejiang Univ Sci A 10: 716-724.

44. Allen SJ, McKay G, Khader KY (1989) Intra-particle diffusion of a basic dye during adsorption onto sphagnum peat. Environ Pollut 56: 39-50.

45. ShroffK A, Vaidya VK (2011) Kinetics and equilibrium studies on biosorption of nickel from aqueous solution by dead fungal biomass of Mucor hiemalis. Chem Eng J 171: 1234-1245.

46. Suresh Ch, Reddy DH, Harinath Y, Naik BR, Seshaiah K, et al. (2014) Development of wood apple shell (Feronia acidissima) powder biosorbent and its application for the removal of $\mathrm{Cd}(\mathrm{II})$ from aqueous solution. ScientificWorldJournal 2014: 154809.

47. Namasivayam C, Kavitha D (2002) Removal of Congo Red from water by adsorption onto activated carbon prepared from coir pith, an agricultural solid waste. Dyes Pigments 54: 47-58.

48. Arami M, Limaee NY, Mahmoodia NM (2008) Evaluation of the adsorption kinetics and equilibrium for the potential removal of acid dyes using a biosorbent. Chem Eng J 139: 2-10.

49. Wang BE, Hu YY, Xie L, Peng K (2008) Biosorption behavior of azo dye by inactive CMC immobilized Aspergillus fumigatus beads. Bioresour Technol 99: 794-800.

50. Tsezos M (1983) The role of chitin in uranium adsorption by $R$. arrhizus Biotechnol Bioeng 25: 2025-2040.

51. Arica MY, Bayramoglu G (2005) Cr(VI) biosorption from aqueous solutions using free and immobilized biomass of Lentinus sajor-caju: Preparation and kinetic characterization. Colloid Surface A 253: 203-211.

52. Chen Z, Deng H, Chen C, Yang Y, Xu H (2014) Biosorption of malachite green from aqueous solutions by Pleurotus ostreatus using Taguchi method. J Environ Health Sci Eng 12: 63.

53. Han MH, Yun YS (2007) Mechanistic understanding and performance enhancement of biosorption of reactive dyestuffs by the waste biomass generated from amino acid fermentation process. Biochem Eng J 36: 2-7.

54. Tsezos M, Volesky B (1982) The mechanism of uranium biosorption by Rhizopus arrhizus. Biotechnol Bioeng 24: 385-401.

55. Florence JAK, Gomathi T, Thenmozhi N, Sudha PN (2015) Adsorption study: Removal of nickel ions using Kenaf fiber/chitosan biosorbent. J Chem Pharm Res 7: 410-422.

56. Yang Y, Li Z, Wang G, Zhao XP, Crowley DE, et al. (2012) Computational identification and analysis of the key biosorbent characteristics for the biosorption process of Reactive Black 5 onto fungal biomass. PLOS one 7 .

57. Ramrakhiani L, Majumder R, Khowala S (2011) Removal of hexavalent chromium by heat inactivated fungal biomass of Termitomyces clypeatus: Surface characterization and mechanism of biosorption. Chem Eng $\mathrm{J} 171$ : 1060-1068.

58. Shawabkeh RA (2006) Adsorption of chromium ions from aqueous solution by using activated carbo-aluminosilicate material from oil shale. J Colloid Interface Sci 299: 530-536.
59. Al-Degs $Y$, Khraisheh MAM, Allen S Ahmad MN (2000) Effect of carbon surface chemistry on the removal of reactive dyes from textile effluent. Water Res 34 927-935.

60. Crini G, Badot P (2008) Application of chitosan, a natural aminopolysaccharide for dye removal from aqueous solutions by adsorption processes using batch studies: A review of recent literature. Prog Polym Sci 33: 399-447.

61. Giles CH, Smith D, Huitson A (1974) A general treatment and classification of the solute adsorption isotherm. J Colloid Interf Sci 47: 755-765.

62. Ilhan S, Iscen CF, Caner N, Kiran I (2008) Biosorption potential of dried Penicillium restrictum for Reactive Orange 122: Isotherm, kinetic and thermodynamic studies. J Chem Technol Biotechnol 83: 569-575.

63. Tewari N, Vasudevan P, Guha BK (2005) Study on biosorption of Cr (VI) by Mucor hiemalis. Biochem Eng J 23: 185-192.

64. Juang RS, Tseng RL, Wu FC, Lee SH (1997) Adsorption behaviour of reactive dyes from aqueous solutions on chitosan. J Chem Tech Biotechnol 70: $391-$ 399.

65. Günes E, Kaygusuz T (2013) Adsorption of Reactive Blue 222 onto an industrial solid waste included $\mathrm{Al}(\mathrm{III})$ hydroxide: $\mathrm{pH}$, ionic strength, isotherms, and kinetics studies. Desalin Water Treat 8: 1-8.

66. Bai RS, Abraham TE (2001) Biosorption of $\mathrm{Cr}$ (VI) from aqueous solution by Rhizopus nigricans. Bioresour Technol 79: 73-81.

67. Aksu Z, Tezer S (2005) Biosorption of reactive dyes on the green alga Chlorella vulgaris. Process Biochem 40: 1347-1361.

68. Aksakal O, Ucun H (2010) Equilibrium, kinetic and thermodynamic studies of the biosorption of textile dye (Reactive Red 195) onto Pinus sylvestris L. J Hazard Mater 181: 666-672.

69. Jadhav DN, Vanjara AK (2004) Adsorption kinetics study: Removal of dye stuff effluent using sawdust, polymerized sawdust and sawdust carbon-II. Indian J Chem Technol 11: 42-50.

70. Kumar KV, Porkodi K (2007) Mass transfer, kinetics and equilibrium studies for the biosorption of methylene blue using Paspalum notatum. J Hazard Mater 146: $214-226$.

71. Arami M, Limaee NY, Mahmoodi NM, Tabrizi NS (2005) Removal of dyes from colored textile wastewater by orange peel adsorbent: Equilibrium and kinetic studies. J Colloid Interface Sci 288: 371-376.

72. Jain M, Garg VK, Kadirvelu K (2009) Chromium(VI) removal from aqueous system using Helianthus annuus (sunflower) stem waste. J Hazard Mater 162 : 365-372.

73. Patel R, Suresh S (2008) Kinetic and equilibrium studies on the biosorption of reactive black 5 dye by Aspergillus foetidus. Bioresour Technol 99: 51-58.

74. Gupta VK, Srivastava SK, Tyagi R (2000) Design parameters for the treatment of phenolic wastes by carbon columns (obtained from fertilizer waste material) Water Res 34: 1543-1550.

75. Uzun I (2006) Kinetics of the adsorption of reactive dyes by chitosan. Dyes Pigments 70: 76-83. 